\title{
Risco para contração de uma doença sexualmente transmissível na percepção de adolescentes
}

Risk for contraction of a sexuality transmitted disease in perception of adolescents

Riesgo de contraer una enfermedad de transmisión sexual en la percepción de los adolescentes

Patrick Leonardo Nogueira da Silva ${ }^{1}$; Franklin Máximo Silva ${ }^{2}$; Andra Aparecida Dionízio Barbosa ${ }^{3}$; José Ronivon Fonseca ${ }^{4}$

\section{Resumo}

A adolescência é uma etapa do ciclo vital marcada por um complexo processo de crescimento e desenvolvimento biopsicossocial. Este estudo objetiva identificar os riscos para a contração de uma doença sexualmente transmissível na percepção de adolescentes de uma Estratégia de Saúde da Família. Trata-se de um estudo descritivo, de caráter investigativo, com abordagem qualitativa realizado com 15 adolescentes cadastrados em uma Estratégia de Saúde da Família de uma cidade da região norte de Minas Gerais, Sudeste do Brasil. Para a coleta de dados, foi utilizada uma entrevista semiestruturada na qual os depoimentos foram gravados e transcritos na íntegra para posterior categorização e análise. O estudo evidencia que a maior parte dos entrevistados não teve iniciação sexual em sua adolescência, todos conhecem sobre estas doenças, seus mecanismos de transmissão, prevenção e consequências. A televisão e os professores são a principal fonte de atualização, já que para a maioria o diálogo com os pais não existe. Conclui-se que os participantes têm acesso às informações, porém as famílias pouco os orientam.

Descritores: Saúde do adolescente, Doenças sexualmente transmissíveis, Risco, Sexo

\begin{abstract}
The adolescence is a stage of the life cycle marked by a complex process of growth and biopsychosocial development. This study aims to identify the risk for contracting of a sexually transmitted disease in the perception of adolescents from a Family Health Strategy. This is a descriptive study, of investigative character, with qualitative approach conducted with 15 adolescents enrolled in a Family Health Strategy in a city in the North of Minas Gerais, southeastern Brazil. To collect data, we used a semi-structured in which responses were recorded and transcribed for subsequent classification and analysis. The study shows that most respondents did not have sexual initiation in their teens, they all know about these diseases, their mechanisms of transmission, prevention and consequences. Television and the teachers are the main source update, since for most of the dialogue with parents there. We conclude that participants have access to
\end{abstract}

\footnotetext{
${ }^{1}$ Especialista em Saúde da Família e Didática do Ensino Superior pela Universidade Estadual de Montes Claros (UNIMONTES), Montes Claros, Minas Gerais, MG. Enfermeiro da Secretaria Municipal de Saúde de Espinosa (MG). Avenida Juscelino Kubitscheck, s/nº, Santa Tereza, Espinosa, MG, Brasil. email: patrick_mocesp70@ hotmail.com

${ }^{2}$ Especialista em Planejamento Orçamentário do Sistema Único de Saúde pela Pontifícia Universidade Católica de Minas Gerais (PUC-Minas), Belo Horizonte, Minas Gerais, MG. Enfermeiro do Hospital Aroldo Tourinho de Montes Claros (MG). Avenida João XXIII, nº 1.207, Edgar Pereira, Montes Claros, MG, Brasil. email: franklinmaximo10@yahoo.com.br

${ }^{3}$ Mestre em Enfermagem pela Universidade Federal de São Paulo (UNIFESP). Professora do Curso de Enfermagem das Faculdades Unidas do Norte de Minas (FUNORTE), Montes Claros, Minas Gerais, MG. Avenida Osmane Barbosa, $\mathrm{n}^{\mathrm{o}}$ 11.111, JK, Montes Claros, MG, Brasil. email: andrabh@ hotmail.com

${ }^{4}$ Mestrando em Ciências da Saúde pela Universidade Estadual de Montes Claros (UNIMONTES). Professor do Curso de Enfermagem das Faculdades Unidas do Norte de Minas (FUNORTE), Montes Claros, Minas Gerais, MG. Avenida Osmane Barbosa, n 11.111, JK, Montes Claros, MG, Brasil. email: pisecfunorte@ yahoo.com.br
} 
ISSN 2179-6750

information, but families just guide them.

Key-words: Adolescent health, Sexually transmitted disease, Risk, Sex

\section{Resumen}

La adolescencia es una etapa del ciclo de vida marcada por un complejo proceso de crecimiento y desarrollo biopsicosocial. Este estudio tiene como objetivo identificar el riesgo de contraer una enfermedad de transmisión sexual en la percepción de los adolescentes de una Estrategia Salud de la Familia. Trata de un estudio descriptivo, investigativo, con un enfoque cualitativo realizado con 15 adolescentes matriculados en una estrategia de salud familiar en una ciudad en el norte de Minas Gerais, Sureste de Brasil. Para recoger datos, se utilizó una semiestructurado en el que fueron grabadas y transcritas para su posterior análisis y categorización respuestas. El estudio muestra que la mayoría de los encuestados no tienen la iniciación sexual en la adolescencia, todos saben acerca de estas enfermedades, sus mecanismos de transmisión, prevención y consecuencias. La televisión y los profesores son la principal fuente de actualización, ya que la mayor parte no dialogan con los padres. Concluye que los participantes tienen acceso a la información, pero algunas familias no los guían.

Palabras-claves: Salud del adolescente, Enfermedades de transmisión sexual, Riesgo, Sexo

\section{Introdução}

A adolescência é a etapa da vida compreendida entre a infância e a fase adulta marcada por um complexo processo de crescimento e desenvolvimento biopsicossocial ${ }^{1}$.

A população adolescente no Brasil, compreendida entre 10-19 anos de idade, corresponde a um percentual de $21 \%$ da população nacional, segundo o último censo do Instituto Brasileiro de Geografia e Estatística (IBGE). Trata-se de um grupo com grande expressividade populacional, compondo-se em 35.302.872 adolescentes, dos quais 50,4\% são homens e 49,6\% são mulheres. Segundo dados do IBGE, o mesmo ainda complementa que 49\% destes adolescentes são negros e $51 \%$ definem-se como brancos ${ }^{2}$.

A Lei $n^{\circ}$ 8.069, de 13 de junho de 1990, assegura os seguintes direitos aos adolescentes: atenção primária à saúde como promoção de programas de assistência médica e odontológica; atenção secundária, como atendimento médico, farmacêutico, recursos para tratamento; e atenção terciária, como habilitação ou reabilitação na qual os estabelecimentos de saúde deverão proporcionar condições adequadas para os pais, responsáveis ou representantes legais para poder acompanhar os adolescentes em casos de internações ${ }^{2}$.

Os adolescentes são o grupo etário com maior exposição para contrair uma doença sexualmente transmissível (DST), tal como a Acquired Immunodeficiency Syndrome (AIDS), também conhecida por Síndrome da Imunodeficiência Adquirida (SIDA), dentre muitas outras, e isso se deve às características intrínsecas ao período de grande transformação e ao perfil 
ISSN 2179-6750

socioeconômico em que se encontra inserida a grande maioria dos adolescentes brasileiros ${ }^{3}$.

Na população entre 13 e 24 anos, o número de casos acumulados de DST/AIDS é de 54.964, dos quais 31.355 adolescentes são do sexo masculino e 23.609 são do sexo feminino, indicando nitidamente uma questão de gênero e os fatores de vulnerabilidade e prevenção. Além dos adolescentes iniciarem a vida sexual mais cedo, alia-se a isso a desinformação, a prática do sexo desprotegido e a escolha imatura do parceiro ${ }^{3}$.

O adolescente busca, no seu autoconhecimento, estabelecer sua independência e autonomia. Também procura desenvolver seus próprios princípios e direcionar seus sentimentos relacionados à sexualidade. É uma época de descobertas e experimentações novas na qual podem conduzi-lo a riscos irreversíveis, tal como nos casos de uma gravidez indesejada, ocorrências de DST (gardnerella, papilomavírus humano [HPV], tricomoníase, dentre outras), e o que é pior, do Human Immunodeficiency Virus (HIV) ou Vírus da Imunodeficiência Humana (VIH). Conhecimentos e habilidades para lidar com situações de risco às quais o adolescente está exposto devem atingir essa população antes que hábitos comportamentais arriscados sejam adotados ou firmemente estabelecidos ${ }^{4}$.

Jovens adolescentes são detentores de maior conhecimento sobre prevenção de DST que os adultos, embora essa compreensão seja escassa e insuficiente para promover um comportamento sexual seguro. Entre adolescentes com níveis distintos de conhecimento sobre transmissão e prevenção de DST, os que apresentam maior nível de conhecimento não necessariamente se protegeram do risco de contrair uma infecção ${ }^{5}$.

A precocidade no início das relações sexuais e o despreparo dos jovens para a vida sexual ativa e o sexo seguro têm sido apontados como as principais razões da gravidez não desejada na adolescência. Estas mesmas razões também são apontadas para a incidência das DST entre a população jovem em razão do não uso do preservativo, justificado por uma multiplicidade de motivos que passam desde o desconhecimento de como usá-los, seu custo e até o incômodo que causa ${ }^{6}$.

Mesmo com o avanço científico e tecnológico das últimas décadas, nota-se que a evolução não se processa de maneira homogênea, sendo a sexualidade um tema impregnado de mitos. Este assunto se reveste de massa compacta de contradições, tabus e ignorância a tal ponto que nos dias atuais muitas pessoas consideram este tema como exclusivo para adultos e defendem a ideia de que tal referencial deve ser excluído do âmbito de palestras, cursos e currículos escolares por considerarem-no obsceno. Críticas negativas são feitas quando alguma cena erótica é exibida em filmes e os pais, geralmente, utilizam a técnica do silêncio ou da mentira com seu filho, 
ISSN 2179-6750

principalmente quando emerge algum questionamento sobre o assunto ${ }^{6}$.

É nesta fase em que apresenta a maior incidência de DST. Aproximadamente $25 \%$ de todas estas infecções são diagnosticadas em jovens com menos de 25 anos. Dados de âmbito mundial revelam que mais de $30 \%$ das adolescentes sexualmente ativas têm teste positivo para infecção por clamídia (Chlamydia), e que aproximadamente $40 \%$ foram infectadas pelo HPV. A infecção pelo vírus do herpes genital aumentou em mais de 50\%. Os índices de infecção por gonorréia nos intervalos etários entre 15 e 19 anos são os maiores comparados com outras faixas de idade, e mais de $25 \%$ dos novos casos de infecção pelo HIV ocorrem entre jovens com menos de 22 anos ${ }^{5}$.

As DST são causadas por vários agentes e transmitidas, principalmente, por contato sexual sem o uso de preservativo (camisinha), com uma pessoa que esteja infectada e, geralmente, se manifestam por meio de feridas, corrimentos, bolhas ou verrugas. A sua transmissão acontece por meio da relação homossexual ou heterossexual, principalmente quando há penetração, entretanto a relação sexual oral pode transmitir os agentes patogênicos ${ }^{3}$.

Diante disso, o problema posto para investigação tem a seguinte questão norteadora: Quais os riscos para a contração de uma DST na percepção de adolescentes de uma Estratégia de Saúde da Família (ESF).

Diante do exposto, este estudo objetiva identificar os riscos para a contração de uma DST na percepção de adolescentes de uma ESF.

\section{Metodologia}

Trata-se de um estudo descritivo, de caráter investigativo, com abordagem qualitativa.

O local para a realização deste estudo se deu na ESF do Bairro Cintra localizada na cidade de Montes Claros, Minas Gerais. Esta Unidade de Saúde tem 1.007 famílias cadastradas, com uma população total de 3.834 membros familiares, sendo 769 na faixa etária de 10 a 19 anos.

Os sujeitos do estudo foram os adolescentes cadastrados na ESF do Bairro Cintra, Montes Claros/MG, na qual se apresentavam na média de idade entre 13 e 18 anos. Foram selecionados 15 adolescentes para compor a amostra desta pesquisa.

O estudo foi realizado durante o primeiro semestre de 2010 (de 14 a 27 de maio) pelo pesquisador responsável.

Foram adotados os seguintes critérios de inclusão para participação na pesquisa: ter entre 13 e 18 anos de idade; estar cadastrados na ESF do Bairro Cintra/Montes Claros/MG; aceitar participar da pesquisa; e ter autorização do responsável legal para participar. Foram excluídos aqueles que, mesmo preenchendo os critérios de inclusão, não compareceram ao local da entrevista. 
ISSN 2179-6750

Como instrumento de coleta de dados, foi utilizada uma entrevista semiestruturada na qual os depoimentos dos entrevistados foram registrados por meio de um gravador e transcritos na íntegra para posterior discussão dos dados.

A entrevista foi realizada mediante a assinatura do Termo de Consentimento Livre e Esclarecido (TCLE) pelos responsáveis legais dos adolescentes em se tratando de menores de idade.

Durante o estudo dos dados coletados, foram atribuídos a estes quatro categorias norteadoras da pesquisa, sendo estas: $1^{\circ}$ ) Perfil dos adolescentes; $2^{\circ}$ ) Conhecimento dos adolescentes sobre as DST; $3^{\circ}$ ) Fonte de conhecimento sobre as DST; e $4^{\circ}$ ) Medo de contrair uma DST.

O tratamento dos dados se deu por meio da Análise de Conteúdo ${ }^{7}$. A mesma, enquanto método, torna-se um conjunto de técnicas de análise das comunicações que utiliza procedimentos sistemáticos e objetivos de descrição do conteúdo das mensagens.

Os participantes foram descritos utilizando-se letras do alfabeto latino e números (M1 a M6; F1 a F9) de forma a manter o sigilo e o anonimato dos participantes, sendo M (Masculino) e F (Feminino).

O estudo obedeceu aos preceitos éticos estabelecidos pela Resolução nº 196/96 do Conselho Nacional de Saúde (CNS) na qual regulamenta a pesquisa envolvendo seres humanos. O projeto de pesquisa foi aprovado pelo Comitê de Ética em Pesquisa das Faculdades Unidas do Norte de Minas (CEP FUNORTE) sob parecer consubstanciado nº 029/2010.

\section{Resultados e Discussão}

Perfil dos adolescentes

A entrevista foi realizada com 15 adolescentes, sendo nove do sexo feminino e seis do sexo masculino. Os entrevistados tinham entre 13-18 anos, sendo a média de idade de 15 anos. Em relação à escolaridade, sete dos adolescentes apresentam Ensino Fundamental incompleto; seis, Ensino Médio incompleto; e dois possuem o Ensino Médio completo. Onze dos entrevistados residem com seus pais, três moram com tios e uma mora com a avó. A renda mensal (familiar) média é de 1,62 salários mínimos. Nove declaram ter namorado pelo menos uma vez, e três já iniciaram a atividade sexual, sendo que um dos adolescentes já praticou atividade sexual sem proteção. O início da atividade sexual (IAS) dos adolescentes é, em média, 13,6 anos de idade. 
ISSN 2179-6750

Quadro A. Perfil socioeconômico e demográfico dos adolescentes da pesquisa. Montes Claros (MG), 2010. (continua)

\begin{tabular}{|c|c|c|c|c|c|c|}
\hline Adolescente & Idade & Escolaridade & $\begin{array}{c}\text { Reside } \\
\text { com }\end{array}$ & $\mathbf{R F}^{1}$ & $\begin{array}{c}\mathbf{N}^{\mathbf{0}} \text { de } \\
\text { relações }\end{array}$ & IAS $^{2}$ \\
\hline M1 & 14 & $\begin{array}{c}1^{\circ} \text { grau } \\
\text { incompleto }\end{array}$ & Pais & $\mathrm{R} \$ 600,00$ & 01 & Não teve \\
\hline M2 & 18 & $\begin{array}{l}2^{\circ} \text { grau } \\
\text { completo }\end{array}$ & Pais & $\mathrm{R} \$ 900,00$ & 04 & 15 anos \\
\hline M3 & 17 & $\begin{array}{c}2^{\circ} \text { grau } \\
\text { incompleto }\end{array}$ & Pais & Não sabe & 01 & Não teve \\
\hline M4 & 18 & $\begin{array}{c}2^{\circ} \text { grau } \\
\text { incompleto }\end{array}$ & Avós & $\mathrm{R} \$ 2500,00$ & 01 & 12 anos \\
\hline M5 & 15 & $\begin{array}{c}2^{\circ} \text { grau } \\
\text { incompleto }\end{array}$ & Pais & $\mathrm{R} \$ 510,00$ & Não teve & Não teve \\
\hline M6 & 14 & $\begin{array}{c}2^{\circ} \text { grau } \\
\text { incompleto }\end{array}$ & Pais & $\mathrm{R} \$ 510,00$ & 01 & Não teve \\
\hline F1 & 16 & $\begin{array}{c}1^{\circ} \text { grau } \\
\text { incompleto }\end{array}$ & Tios & $\mathrm{R} \$ 510,00$ & 02 & 14 anos \\
\hline F2 & 13 & $\begin{array}{c}1^{\circ} \text { grau } \\
\text { incompleto }\end{array}$ & Pais & $\mathrm{R} \$ 1200,00$ & Não teve & Não teve \\
\hline F3 & 18 & $\begin{array}{c}1^{\circ} \text { grau } \\
\text { incompleto }\end{array}$ & Tios & $\mathrm{R} \$ 1200,00$ & Não teve & Não teve \\
\hline F4 & 15 & $\begin{array}{c}1^{\circ} \text { grau } \\
\text { incompleto }\end{array}$ & Pais & $\mathrm{R} \$ 600,00$ & 04 & Não teve \\
\hline F5 & 18 & $\begin{array}{c}2^{\circ} \text { grau } \\
\text { completo }\end{array}$ & Pais & $\mathrm{R} \$ 1200,00$ & $\begin{array}{c}\text { Não } \\
\text { informou }\end{array}$ & $\begin{array}{c}\text { Não } \\
\text { informou }\end{array}$ \\
\hline F6 & 13 & $\begin{array}{c}1^{\circ} \text { grau } \\
\text { incompleto }\end{array}$ & Pais & $\mathrm{R} \$ 510,00$ & Não teve & Não teve \\
\hline F7 & 17 & $\begin{array}{c}2^{\circ} \text { grau } \\
\text { completo }\end{array}$ & Pais & $\mathrm{R} \$ 510,00$ & 02 & $\begin{array}{c}\text { Não } \\
\text { informou }\end{array}$ \\
\hline F8 & 16 & $\begin{array}{c}2^{\circ} \text { grau } \\
\text { incompleto }\end{array}$ & Pais & $\mathrm{R} \$ 1200,00$ & Não teve & Não teve \\
\hline F9 & 17 & $\begin{array}{c}2^{\circ} \text { grau } \\
\text { incompleto }\end{array}$ & Tia & $\mathrm{R} \$ 510,00$ & 02 & Não teve \\
\hline
\end{tabular}

Fonte: Adolescentes cadastrados na ESF do Bairro Cintra. Montes Claros (MG), 2010.

${ }^{I} R F=$ Renda Familiar $;{ }^{2} I A S=$ Início da Atividade Sexual.

A adolescência é um momento de diversas transformações sociais, emocionais, corporais e cognitivas e também o período do desenvolvimento humano no qual a maioria dos jovens inicia a vida sexual. Segundo diretrizes da Organização Pan-Americana de Saúde (OPAS) e a Organização Mundial de Saúde (OMS), a adolescência abrange a faixa etária de 10 a 19 anos, sendo um processo essencialmente biológico pelo qual ocorre um acelerado desenvolvimento cognitivo e a estruturação da personalidade. Esse grupo representa 21,7\% da população brasileira, sem do 11,1\% entre 10 e 14 anos e $10,6 \%$ entre 15 e $19^{8}$. 
ISSN 2179-6750

Atualmente, os adolescentes estão iniciando mais cedo as relações sexuais e ao mesmo tempo com um número maior de parceiros, e sem a devida programação do ato sexual seguro, o que contribui para a propagação da DST nesta faixa etária ${ }^{9}$.

Segundo dados da OMS, a grande maioria dos jovens adolescentes iniciam sua vida sexual cada vez mais cedo, a maioria entre 12 e 17 anos, desacompanhada de responsabilidade social que tem seu início cada vez mais tardio ${ }^{10}$.

\section{Conhecimento dos adolescentes sobre DST}

Dentre os relatos dos participantes, observou-se que os mesmos responderam que as DST são doenças contagiosas, transmitidas através da relação sexual e somente podem ser evitadas através do uso da camisinha. Durante a entrevista, os adolescentes se referem à morte como um resultado à aquisição de uma DST. Tais questionamentos podem ser observados nos depoimentos transcritos a seguir:

“Ela é transmitida pela relação sexual sem preservativo e ela pode causar a morte”. (M4)

“Esse tipo de doença só é transmitido através do ato sexual. Um exemplo de doença sexualmente transmissivel é o HIV e atualmente atinge milhares de pessoas no mundo”. (M5)

"Que são transmitidas no sexo e só evitadas usando camisinha”. (M1)

"Se não nos protegermos nas relações, essas doenças podem causar até a morte”. (F9)

"[...] que algumas não têm cura e que o quanto mais cedo a doença for descoberta melhor". (F8)

O fato abordado sugere que, ao falar de DST, a mesma traz à lembrança o advento da AIDS e de suas consequências, evidenciando que os adolescentes sabem sobre a forma de transmissão e também que estas doenças, em particular a infecção pelo vírus HIV, pode levar uma pessoa à morte.

A maioria dos jovens demonstra conhecimento sobre as formas de prevenção da transmissão das DST por meio do uso de preservativo ${ }^{11}$.

Quando questionados sobre as formas de contaminação por uma DST, foi evidenciado que o ato sexual sem o uso de camisinha é uma das principais formas de transmissão das DST, dentre elas o HIV/AIDS, bem como o uso de seringas contaminadas, objetos cortantes e hemoderivados contaminados. Ficou também evidente que as DST mais conhecidas pelo público jovem são: a AIDS, principalmente, gonorreia e a sífilis, sendo o HPV o menos citado. Houve um adolescente que não soube citar nenhuma DST no momento. 
"Seringas contaminadas, transfusão de sangue, ter relação com pessoas contaminadas sem usar camisinha, etc. AIDS, sífilis e gonorréia”. (F2)

"Transfusão de sangue contaminado, pelo sexo sem proteção, seringas contaminadas e outras. DST que conheço: AIDS, gonorréia, sifilis e outras”. (M2)

"Praticando o ato sexual sem camisinha e através de objetos cortantes não esterilizados. AIDS, candidiase, hepatite, etc”. (F5)

"Sexo sem camisinha, seringas contaminadas. AIDS e herpes". (F3)

Em outros estudos, o conhecimento sobre as DST foi avaliado para todas as adolescentes entrevistadas. Os resultados indicaram que elas conhecem, em média, de cinco a seis doenças que podem ser transmitidas pelo contato sexual, sendo a AIDS citada por todas as adolescentes $(92,2 \%$ de forma espontânea e 7,8\% de forma estimulada). No entanto, observou-se que muitas ainda desconheciam doenças como a sífilis $(35,6 \%)$, herpes genital $(33,3 \%)$, gonorreia $(30 \%)$ e HPV $(27,7 \%)^{11}$.

Fonte de conhecimentos dos adolescentes sobre as DST

Ao levantar questionamentos em relação às fontes de informação sobre o assunto abordado, observou-se que a maioria dos entrevistados citou a televisão e em seguida o posto de saúde, jornais, informação familiar (mãe), amigos e panfletos.

\footnotetext{
“Apenas a televisão”. (M1)

"Nas escolas, posto de saúde e jornais”. (F1)

“Através de revistas, jornais, propagandas de TV, nas escolas e em posto de saúde”. (F2)

"São fontes de informação sobre as DST: livros, revistas, jornais, internet, televisão, posto de saúde, panfletos". (M5)
}

No estudo de Possebon e Lazzarotto ${ }^{12}$, é observado que a fonte de informação dos adolescentes sobre o tema exposto era a escola $(97,3 \%)$, os pais $(59,5 \%)$, amigos $(21,6 \%)$ e os profissionais de saúde $(5,4 \%)$.

Quando questionados sobre o diálogo com seus pais sobre sexo, pôde-se evidenciar que a maioria dos entrevistados nunca conversou com seus pais sobre o assunto deixando evidente que o motivo de não abordar tal assunto é, frequentemente, devido ao medo e/ou vergonha de iniciar a conversa. Já outros citaram a falta de oportunidade. Apenas dois dos adolescentes relatam que conversam com os pais sempre e dois dos entrevistados citaram que às vezes conversam. 
“Não, pois tenho muita vergonha de conversar isto com meus pais”. (F6)

"Não, pois ainda não tive oportunidade de conversar com a minha mãe, pois ela trabalha o dia todo". (F4)

“Sim, sobre doenças sexualmente transmissíveis e métodos contraceptivos". (F5)

“Às vezes sobre relações sexuais, doenças, gravidez indesejada, etc.”. (F7)

No estudo de Almeida e Centa ${ }^{13}$ foi identificado que os pais possuem dificuldades para a orientação sexual dos adolescentes, pois falta coragem para abordá-los em discussões referentes à sexualidade. Tem também o desinteresse e falta de atenção por parte dos adolescentes para ouvi-los.

Desta forma, os entrevistados relataram que quando tem dúvidas a respeito do assunto, os mesmos tiram-nas com seus amigos ou não as tiram. Apenas quatro citaram seus pais e três citaram seus tios e tias. Um adolescente relatou que tira suas dúvidas com pesquisas em livros e internet.

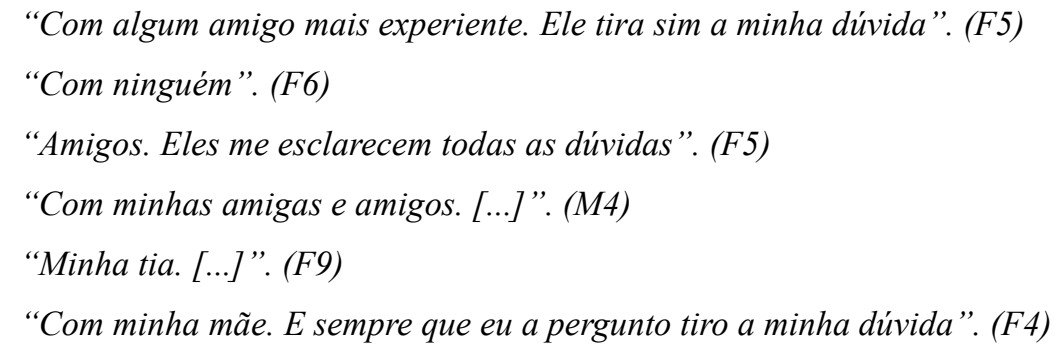

Perguntou-se aos adolescentes se na escola os professores falam sobre as DST e o que estes abordam sobre a temática em sala de aula. Apenas um jovem relatou que os professores não falam sobre o assunto. Ficou evidenciado nos depoimentos que os professores abordam: prevenção das doenças e o que elas causam na vida das pessoas.

\footnotetext{
“Sim. Como acontece, o que causam e como combatê-las”. (F5)

“Eles falam que é muito perigoso e é transmissível”. (M4)

“Falam como prevenir e o que as DST trazem”. (M2)

"Não fala sobre doença sexualmente transmissível”. (F9)

"Falam sobre tudo. Como se prevenir de uma DST, de uma gravidez na adolescência e como é feito o tratamento de uma DST". (M5)
}

\section{Medo de contrair uma DST}

Foram abordados os seguintes aspectos com os adolescentes: ter medo de contrair uma DST; iniciação sexual; e uso de preservativo. Observou-se que doze dos participantes têm medo de 73 
ISSN 2179-6750

contrair algum tipo de DST, principalmente a AIDS. Os que relataram não ter medo justificaram que quando forem iniciar a atividade sexual irão se prevenir com a camisinha. Dos adolescentes que já tiveram relação sexual, um deles relatou que não faz uso do preservativo com frequência, entretanto dois relataram que sempre se protegem.

"Sim. Todas". (M2)

"Sim. Todas, pois todas são perigosas". (F3)

"Não. Pois tenho consciência de que quando for ter relações sexuais irei usar camisinha". (M5)

"A minha primeira vez foi aos 15 anos. Às vezes não uso a camisinha, pois não tenho naquele momento". (M2)

"Aos 12 anos. E uso camisinha sempre". (M4)

"Ainda não fiz (sexo)". (F8)

"Não tive (sexo)". (M3)

Os entrevistados apresentaram baixo risco para se contrair uma DST, pois a maioria deles não iniciou a atividade sexual e estão cientes que o único meio de se prevenir é usando a camisinha nas práticas sexuais, mesmo tendo um dos adolescentes que não faz uso de preservativo com frequência.

\section{Considerações Finais}

Observa-se que a maior parte dos entrevistados não teve iniciação sexual na adolescência. O motivo é subentendido pelo fato de a amostragem ter sido de prevalência do sexo feminino e por residirem com os pais na qual os mesmos não abordam o assunto de forma clara com os filhos fazendo disso um tabu, o que pode levar aos adolescentes a terem um comportamento repressivo com relação ao sexo. Inclusive, da menor parcela da amostra que praticaram o ato sexual, dois são do sexo masculino e não residem com os pais.

O nível de entendimento dos entrevistados sobre DST está bem evidente em seus depoimentos. Contudo, a pesquisa aponta que os mesmos na maioria das vezes quando possuem dúvidas relativas às DST procuram por amigos para esclarecimentos. Sabe-se que, devido ao avanço da tecnologia e da globalização, o acesso às informações está cada vez mais disponível, por isso o cuidado em absorvê-las deve ser considerado importante. Obtêm-se a informação para uma tomada de decisão, e quando a mesma é distorcida poderá ocasionar consequências irreversíveis, ponto este observado na pesquisa quando os participantes fazem analogia entre a AIDS e a morte. 
ISSN 2179-6750

Relatos de medo no estudo sobre adquirir uma DST são entendidos e esperados uma vez que ninguém tem o desejo de contrair qualquer doença que seja. Ademais, o medo tem fator relevante nesta pesquisa porque provoca receio nas pessoas sobre qualquer atitude irresponsável na atividade sexual, reduzindo, assim, as ocorrências de DST.

\section{Referências}

1. Brasil. Ministério da Saúde. Secretaria de Atenção à Saúde. Área de Saúde do Adolescente e do Jovem. Marco legal: saúde - um direito de adolescentes. Brasília (DF), 2005. Disponível em: http://portal.saude.gov.br/portal/arquivos/pdf/marco_legal.pdf

2. Brasil. Ministério da Saúde. Secretaria de Atenção à Saúde. Departamento de Ações Programáticas e Estratégicas. Marco teórico e referencial: saúde sexual e saúde reprodutiva de adolescentes e jovens. Brasília (DF), 2006. Disponível em: http://dtr2001.saude.gov.br/editora/produtos/livros/pdf/06_0611_M.pdf

3. Brasil. Ministério da Saúde. Secretaria de Vigilância em Saúde. Programa Nacional de DST/AIDS. Boletim epidemiológico - AIDS. Brasília (DF), 2007. Disponível em: http://www.aids.gov.br/sites/default/files/Boletim2007_internet090108.pdf

4. Flaskerud J. AIDS: infecção pelo HIV. São Paulo (SP): Medsi, 1992.

5. Martins LBM, Costa-Paiva LHS, Osis MJD, Souza MH, Pinto-Neto AM, Tadini V. Fatores associados ao uso de preservativo masculino e ao conhecimento sobre DST/AIDS em adolescentes de escolas públicas e privadas do Município de São Paulo, Brasil. Cad Saúde Pública [online]. 2006 [acesso em 2009 ago 11];22(2):315-23. Disponível em: http://www.scielo.br/pdf/csp/v22n2/09.pdf

6. Ota YP. Controle das doenças sexualmente transmissíveis [especialização]. Escola de Saúde do Exército. Rio de Janeiro (RJ), 2008. Disponível em: http://www.essex.ensino.eb.br/doc/PDF/PCC_2008_CFO_PDF/CD104\%201\%BA\%20Ten \%20A1\%20YOKO\%20PATRICIA\%20OTA.pdf

7. Bardin L. Análise de conteúdo. Lisboa, Portugal; Edições 70, LDA, 2009.

8. Oliveira DC, Pontes APM, Gomes AMT, Ribeiro MCM. Conhecimentos e práticas de adolescentes acerca das DST/HIV/AIDS em duas escolas públicas municipais do Rio de Janeiro. Esc Anna Nery [online]. 2009 [acesso em 2010 jun 14];13(4):833-41. Disponível em: http://www.scielo.br/pdf/ean/v13n4/v13n4a20.pdf

9. Taquette SR, Vilhena MM, Paula MC. Doenças sexualmente transmissíveis e gênero: um estudo transversal com adolescentes no Rio de Janeiro. Cad Saúde Pública [online]. 2004 
ISSN 2179-6750

[aceso em 2010 jul 29];20(1):282-90. Disponível em: http://www.scielo.br/pdf/csp/v20n1/46.pdf

10. Bretas JRS, Ohara CVS, Jardim DP, Muroya RL. Conhecimento sobre DST/AIDS por estudantes adolescentes. Rev Esc Enferm USP [online]. 2009 [acesso em 2010 mai 12];43(3):551-7. Disponível em: http://www.scielo.br/pdf/reeusp/v43n3/a08v43n3.pdf

11. Doreto DT, Vieira EM. O conhecimento sobre doenças sexualmente transmissíveis entre adolescentes de baixa renda em Ribeirão Preto, São Paulo, Brasil. Cad Saúde Pública [online]. 2007 [acesso em 2009 dez 20];23(10):11-16. Disponível em: http://www.scielosp.org/pdf/csp/v23n10/26.pdf

12. Possebon AT, Lazzarotto EM. Orientação sexual dos adolescentes em tempos de DST/AIDS. $2^{\circ}$ Seminário Nacional Estado e Políticas Sociais no Brasil. Unioeste. Cascavel (SP), 2006. Disponível em: http://cac-php.unioeste.br/projetos/gpps/midia/seminario2/poster/educacao /pedu23.pdf

13. Almeida ACCH, Centa ML. A família e a educação sexual dos filhos: implicações para a enfermagem. Acta Paul Enferm [online]. 2009 [acesso em 2010 mar 20];22(1):71-6. Disponível em: http://www.scielo.br/pdf/ape/v22n1/a12v22n1.pdf 